\title{
Association of echocardiography before major elective non-cardiac surgery with postoperative survival and length of hospital stay: population based cohort study
}

\author{
Duminda N Wijeysundera assistant professor ${ }^{123}$, W Scott Beattie professor ${ }^{2}$, Keyvan Karkouti \\ associate professor ${ }^{24}$, Mark D Neuman assistant professor ${ }^{56}$, Peter C Austin professor ${ }^{34}$, Andreas \\ Laupacis professor ${ }^{1347}$
}

\begin{abstract}
${ }^{1}$ Keenan Research Centre, Li Ka Shing Knowledge Institute of St Michael's Hospital, 80 Bond Street, Toronto, ON, Canada M5B 1W8; ${ }^{2}$ Department of Anesthesia, Toronto General Hospital and University of Toronto, Toronto; ${ }^{3}$ Institute for Clinical Evaluative Sciences, Toronto; ${ }^{4}$ Department of Health Policy Management and Evaluation, University of Toronto; ${ }^{5}$ Department of Anesthesiology and Critical Care, School of Medicine, University of Pennsylvania, Philadelphia, PA, USA; ${ }^{6}$ Leonard Davis Institute for Health Economics, University of Pennsylvania; ${ }^{7}$ Department of Medicine, St Michael's Hospital and University of Toronto
\end{abstract}

\begin{abstract}
Objective To determine the association of resting echocardiography before elective intermediate to high risk non-cardiac surgery with survival and length of hospital stay.

Design Population based retrospective cohort study.

Setting Acute care hospitals in Ontario, Canada, between 1 April 1999 and 31 March 2008.

Participants Patients aged over 40 years who had elective intermediate to high risk non-cardiac surgery.

Intervention Resting echocardiography within 6 months before surgery.

Main outcome measures Postoperative survival (30 days and 1 year) and length of hospital stay; postoperative surgical site infection as an outcome for which no association with echocardiography would be expected.

Results Of the 264823 patients in the entire cohort, $15.1 \%(n=40084)$ had echocardiography. After use of propensity score methods to assemble a matched cohort $(n=70996)$ that reduced differences between patients who had or had not had echocardiography, echocardiography was associated with increases in 30 day mortality (relative risk 1.14, $95 \%$ confidence interval 1.02 to 1.27$), 1$ year mortality $(1.07,1.01$ to 1.12), and length of hospital stay but no difference in surgical site infections $(1.03,0.98$ to 1.06$)$. The association with mortality was influenced $(P=0.02)$ by whether patients had had stress testing or had risk factors for cardiac complications. No association existed between echocardiography and mortality among patients who had stress testing (relative risk 1.01, 0.92 to 1.11 ) or among patients at high risk who had not had stress testing (1.00, 0.87 to 1.13$)$. However, echocardiography was associated with mortality in patients at low risk (relative risk 1.44, 1.14 to 1.82$)$ and intermediate risk $(1.10,1.02$ to 1.18$)$ who had not had stress testing.
\end{abstract}

Conclusions Preoperative echocardiography was not associated with improved survival or shorter hospital stay after major non-cardiac surgery. These findings highlight the need for further research to guide better use of this common preoperative test.

\section{Introduction}

Perioperative cardiac complications are an important concern for the 234 million people every year who have major surgery worldwide. ${ }^{1}$ Cardiac complications occur after at least $2 \%$ of elective non-cardiac procedures and account for a third of postoperative deaths. ${ }^{23}$ Consensus based guidelines recommend preoperative risk stratification in an attempt to prevent these complications. ${ }^{4}$ Accurate estimates of perioperative cardiac risk will identify people who may benefit from optimisation of chronic medical treatment, interventions such as $\beta$ blockade or coronary revascularisation, aggressive haemodynamic management, closer postoperative surveillance, or avoidance of surgery.

As predictive indices based on readily available clinical risk factors have limitations, ${ }^{5}$ clinicians sometimes use specialised cardiac tests to improve estimation of perioperative risk. Recent population based studies suggest that the specialised cardiac test most commonly ordered before major non-cardiac surgery is resting echocardiography. ${ }^{6-8}$ Echocardiography offers advantages because it is readily available and does not require intravenous injection, radioactive isotopes, or exposure to radiation. ${ }^{9}$ It also provides information on ventricular dysfunction and valvular abnormalities, as well as on fixed wall motion abnormalities that suggest previous myocardial infarction. However, some authors have suggested that information derived from echocardiography does not provide 
additional prognostic information when combined with readily available clinical risk factors. ${ }^{9}$

Given its relatively common use,,$^{6-8}$ understanding whether information derived from preoperative echocardiography improves perioperative care and outcomes is important. Specifically, if echocardiography results in improved clinical outcomes, its increased use is justified. However, if it does not, the relatively common use of echocardiography represents an unnecessary healthcare cost that may also unnecessarily delay scheduled surgeries. Notably, echocardiography could worsen outcomes if it provides inaccurate prognostic information. For example, a normal echocardiogram may provide false reassurance of low cardiac risk. Conversely, an abnormal echocardiogram may misclassify patients as being at high risk, thereby exposing them to unnecessary and potentially harmful interventions, such as perioperative $\beta$ blockade. ${ }^{3}$

No randomised controlled trial has yet evaluated the effect of preoperative echocardiography on postoperative outcomes. We therefore did a population based cohort study in Ontario, Canada, to determine whether echocardiography before elective intermediate to high risk non-cardiac surgery was associated with improved survival and shorter hospital stay.

\section{Methods}

We did a retrospective cohort study in Ontario, Canada, using the following linked population based administrative healthcare databases: the Discharge Abstract Database of the Canadian Institute for Health Information (hospital admissions), the Ontario Health Insurance Plan database (physicians' service claims), the Registered Persons Database (vital statistics), the Institute for Clinical Evaluative Sciences Physician Database (physicians' specialties), the Ontario Drug Benefit database (prescription drugs for people aged 65 years or older), and the Canadian census. Although these databases lack physiological and laboratory measures, such as blood pressure or haemoglobin, they have been validated for many outcomes, exposures, and comorbidities. ${ }^{10-13}$ During the study period, Ontario was Canada's most populous province, with more than 12 million residents, all of whom have universal access to physicians' and hospitals' services through a publicly funded healthcare programme.

\section{Cohort}

Using previously described methods, ${ }^{6-8}{ }^{14}$ we identified all Ontario residents aged 40 years or older who had the following elective non-cardiac surgeries between 1 April 1999 and 31 March 2008: abdominal aortic aneurysm repair, carotid endarterectomy, peripheral vascular bypass, total hip replacement, total knee replacement, large bowel resection, partial liver resection, Whipple procedure, pneumonectomy, pulmonary lobectomy, gastrectomy, oesophagectomy, nephrectomy, or cystectomy. We selected these procedures because they carry intermediate to high risk, ${ }^{4}$ are applicable to both sexes, and are previously described in the Discharge Abstract Database. ${ }^{15}{ }^{16}$ Procedural information in this database is very accurate. ${ }^{11}{ }^{13}$ For people who had more than one eligible procedure during the study period, we included only the first procedure.

Using previously described methods, ${ }^{17}$ we used the Ontario Health Insurance Plan database to identify the principal exposure: outpatient preoperative echocardiography (transthoracic or transoesophageal) within 180 days before surgery. Although our data sources could not accurately identify inpatient preoperative echocardiography, this limitation would tend to conservatively bias the results towards the null. The 180 day time window has been previously used for research purposes and allowed for inclusion of cases in which echocardiography may have led to preoperative coronary revascularisation. ${ }^{618}$

We followed patients for one year after surgery for the outcomes of interest-mortality and length of hospital stay. We used the Discharge Abstract Database (in-hospital death, hospital stay) and Registered Persons Database (deaths out of hospital) to ascertain these outcomes. We used a one year follow-up period to ascertain mortality because postoperative cardiac complications are not well captured by administrative databases but are closely associated with increased long term mortality. ${ }^{190}$ Demographic information came from the Registered Persons Database, and we used validated algorithms to identify diabetes mellitus, hypertension, and preoperative medical consultations. ${ }^{10}{ }^{12}{ }^{21}$ We used the Ontario Health Insurance Plan database to identify any patient who needed dialysis before the index surgery. Using the Discharge Abstract Database, we used previously described methods to identify other comorbidities on the basis of ICD-9 or ICD-10 (international classification of diseases, 9th or 10th revision) codes from hospital admissions within three years before surgery: coronary artery disease, congestive heart failure, atrial fibrillation, cardiac valvular disease (aortic or mitral stenosis), cerebrovascular disease, peripheral vascular disease, pulmonary disease, chronic renal insufficiency, previous venous thromboembolism, liver disease, peptic ulcer disease, rheumatological disease, hemiplegia or paraplegia, malignancy, and dementia. ${ }^{22-24} \mathrm{We}$ also used the Discharge Abstract Database to identify previous mechanical aortic or mitral valve replacement procedures within 10 years before surgery. When assessing for comorbidities, we used only information from hospital admissions before the index surgery to ascertain coronary artery disease, congestive heart failure, atrial fibrillation, cerebrovascular disease, renal insufficiency, and venous thromboembolism. Our purpose was to ensure that postoperative complications were not misclassified as comorbidities. ${ }^{25}$

We used the Ontario Health Insurance Plan database to identify preoperative cardiac stress testing (within 180 days before surgery), ${ }^{6}{ }^{17}$ preoperative outpatient anaesthesia consultations, ${ }^{7}$ perioperative epidural anaesthesia or analgesia (hereafter referred to as "anaesthesia"), ${ }^{14}$ and intraoperative invasive monitoring. We estimated patients' socioeconomic status on the basis of their neighbourhood median income in the Canadian census and determined their residence (rural versus urban) by using Statistics Canada's definitions. ${ }^{26}$

To understand how echocardiography might influence outcomes, we used the Discharge Abstract Database to identify preoperative cardiac interventions, and we used the Ontario Drug Benefit database to identify outpatient prescriptions for $\beta$ blockers, statins, angiotensin converting enzyme inhibitors, and angiotensin receptor blockers in patients aged 65 years or older.

\section{Analyses}

We developed a non-parsimonious multivariable logistic regression model to estimate a propensity score for echocardiography. ${ }^{27}$ Clinical significance guided the initial choice of covariates: age, sex, year, surgery, fifth of income, residence (urban $v$ rural), hospital's characteristics (teaching status and volume of procedures), comorbid disease, preoperative medical consultation (general internist, cardiologist), preoperative anaesthesia consultation, epidural anaesthesia, and invasive monitoring. The comorbidities included in the model were coronary artery disease, congestive heart failure, atrial fibrillation, cardiac valvular disease, 
mechanical heart valve, cerebrovascular disease, peripheral vascular disease, hypertension, diabetes, pulmonary disease, renal disease, previous venous thromboembolism, liver disease, peptic ulcer disease, rheumatological disease, hemiplegia or paraplegia, malignancy, and dementia. We used previously described methods to categorise hospitals into quarters, ${ }^{28}$ on the basis of the total volume of included procedures. We used a structured iterative approach to refine this logistic regression model to achieve balance of covariates within the matched pairs. ${ }^{29} \mathrm{We}$ used the standardised difference to measure covariate balance, whereby an absolute standardised difference above $10 \%$ represents meaningful imbalance. ${ }^{29} \mathrm{We}$ then matched (without replacement) patients who had echocardiography to those who did not, by using a greedy matching algorithm with a calliper width of $0.2 \mathrm{SD}$ of the log odds of the propensity score. We used statistical methods appropriate for paired data to compare outcomes. ${ }^{29}$

We did subgroup analyses based on coronary artery disease, congestive heart failure, pulmonary disease, surgery, hospital type, concurrent cardiac stress testing, and the revised cardiac risk index ( 0 points, $1-2$ points, $\geq 3$ points). ${ }^{2}$ For these subgroup analyses, we repeated the propensity score matching process while simultaneously forcing a match on the subgroup characteristics. We then used logistic regression (estimated with generalised estimating equations ${ }^{30}{ }^{31}$ ) to assess for interactions between the exposure and subgroups of interest. As data on outpatient prescriptions are available only for people over 65 years of age, and we used a one year look back period to ascertain preoperative drugs, we did an additional subgroup analysis in patients aged over 66 years.

To test the robustness of our results, we measured the association of echocardiography with an outcome for which no difference would be expected-surgical site infection (Discharge Abstract Database).$^{32}$ The purpose of this "tracer" analysis was to test for residual confounding. As surgical site infection is associated with increased patients' risk status, ${ }^{32}$ but should not be influenced by preoperative echocardiography, we hypothesised that echocardiography would not be associated with increased rates of these infections.

We used SAS version 9.2 for all analyses. We used a two tailed $P$ value less than 0.05 to define statistical significance.

\section{Results}

The cohort consisted of 264823 patients, of whom $15.1 \%$ ( $n=40$ 084) had echocardiography within 180 days before surgery. Patients who did or did not have echocardiography differed significantly for all measured characteristics (tables 1 and 2). Those who had echocardiography were generally older men who had greater burdens of comorbid disease; they were more likely to have had specialist consultations and cardiac stress testing. Additionally, they were more likely to receive epidural anaesthesia and intraoperative invasive monitoring.

We matched approximately $89 \%(n=35498)$ of patients who had echocardiography to similar controls. The covariate balance was considerably improved (tables 3 and 4); the median absolute standardised difference decreased from $12.2 \%$ (range 0.5-83.4\%) to $0.4 \%(0-1.9 \%)$. Within the matched cohort, preoperative echocardiography was associated with a small and statistically significant increase in postoperative mortality, both at 30 days (relative risk 1.14, 95\% confidence interval 1.02 to $1.27 ; \mathrm{P}=0.02$; number needed to harm $(\mathrm{NNH}) 423)$ and at one year $(1.07,1.01$ to $1.12 ; \mathrm{P}=0.02 ; \mathrm{NNH} 222$ ) (table 5). It was also associated with an increase in mean hospital stay $(0.31$ (95\% confidence interval
0.17 to 0.44 ) days; $\mathrm{P}<0.001$ ), but not surgical site infection (relative risk $1.03,0.98$ to $1.06 ; \mathrm{P}=0.18$ ).

Patients who had echocardiography were also more likely to have received new prescriptions for $\beta$ blockers, statins, angiotensin converting enzyme inhibitors, and angiotensin receptor blockers before surgery (table 5). Conversely, they had similar rates of coronary angiography or coronary artery bypass grafting before surgery and lower rates of percutaneous coronary intervention (table 5).

In subgroup analyses, revised cardiac risk index class and concurrent stress testing influenced $(\mathrm{P}=0.02)$ the association of echocardiography with one year mortality (table 6). Among patients who had had stress testing, we found no association between echocardiography and mortality (relative risk 1.01, 0.92 to 1.11 ). Conversely, among those who had not had stress testing, the association of echocardiography with mortality varied with revised cardiac risk index class. It was not associated with mortality in patients at high risk (revised cardiac risk index 3-6 points: relative risk $1.00,0.87$ to 1.13 ) but was associated with increased mortality among those at low risk ( 0 points: 1.44 , 1.14 to $1.82 ; \mathrm{NNH} 163)$ and intermediate risk (1-2 points: 1.10 , 1.02 to 1.18 ; NNH 116 ).

The increased mortality in these subgroups was mirrored by qualitatively similar increases in new prescriptions for $\beta$ blockers and statins (table 7). Specifically, rates of new prescriptions for $\beta$ blockers and statins were relatively higher in the same subgroups in which echocardiography was associated with increased mortality. By comparison, concurrent stress testing and revised cardiac risk index class did not influence (interaction $\mathrm{P}=0.26$ ) the association of echocardiography with new prescriptions for angiotensin converting enzyme inhibitors and angiotensin receptor blockers.

\section{Discussion}

In this population based cohort study, preoperative echocardiography was frequently ordered and was associated with statistically significant, but very small, increases in mortality and length of hospital stay after major elective non-cardiac surgery. The increase in mortality varied according to whether patients had clinical risk factors for perioperative cardiac events or had had non-invasive stress testing. Echocardiography was not associated with any difference in mortality among patients who also had stress testing or among patients at high risk with three or more clinical risk factors. However, it was associated with increased mortality among patients at low to intermediate risk who had not had stress testing. These subgroup specific increases in mortality were mirrored by qualitatively similar increases in perioperative $\beta$ blockade. Conversely, rates of coronary angiography or surgical coronary revascularisation were similar in patients who had had echocardiography, whereas rates of percutaneous coronary intervention were lower.

\section{Influence of unmeasured confounding}

Especially in the context of a non-randomised study, considering whether the increased mortality after echocardiography was simply due to residual unmeasured confounding is important. Specifically, patients who had echocardiography may have been sicker and therefore at increased risk for postoperative complications. Despite our use of statistical methods to adjust for these differences and excellent covariate balance within the matched pairs, our data sources may have lacked sufficient detail to allow adequate adjustment for risk. However, several factors indicate that any residual confounding was small in magnitude 
and unlikely to have masked important benefits from preoperative echocardiography. Firstly, we found no association between echocardiography and the tracer outcome, surgical site infection. Surgical site infection is unlikely to be influenced by echocardiography. However, it is associated with markers of increased perioperative risk, ${ }^{32}$ which include characteristics not captured by administrative data. These risk factors include some comorbidities, such as smoking or obesity, ${ }^{33}{ }^{34}$ as well as the severity of pre-existing diseases. Thus, if residual confounding within the matched pairs was minimal, rates of surgical site infection should be similar, as was the case in our study. Secondly, we found no association between echocardiography and mortality in patients who had concurrent stress testing. Echocardiography is unlikely to provide additional information that will change perioperative management for such patients. Thus, if it was associated with increased mortality in this subgroup, echocardiography may have been a marker for unmeasured risk factors, such as poor exercise capacity. As would be expected in the presence of minimal residual confounding, we found no difference in mortality. Finally, previous studies using these same data sources have found that perioperative interventions (such as epidural anaesthesia or stress testing) that are preferentially used in patients at high risk are nevertheless associated with improved outcomes after adjustment for risk. ${ }^{614}$ These results suggest that our data sources contain sufficient detail for adjustment for confounding.

\section{Interpretation of findings}

Overall, our results suggest that echocardiography, despite being the most commonly ordered specialised preoperative cardiac test, does not provide information that improves outcomes. We found no difference in outcomes in patients at high risk or in those who had had stress testing and worsened outcomes in patients at low to intermediate risk who had not had stress testing. By comparison, cardiac stress testing is associated with decreased survival in patients at low risk but with improved survival in those at intermediate to high risk. ${ }^{6}$ Importantly, these findings apply to resting echocardiography, not stress echocardiography, which accurately stratifies perioperative cardiac risk and is associated with improved outcomes in certain subgroups. ${ }^{65}$ These results are also largely consistent with another population based study of preoperative cardiac testing in American Medicare recipients having vascular surgery. ${ }^{18}$ Fleisher and colleagues found that echocardiography was associated with no unadjusted difference in mortality when done before abdominal aortic aneurysm repair and an unadjusted increase in mortality when done before peripheral vascular bypass surgery.

Several plausible explanations for our findings exist. Firstly, although echocardiography can identify systolic dysfunction, this information has relatively poor prognostic accuracy. In a prospective cohort study of 393 men who had blinded echocardiography before non-cardiac surgery, ${ }^{9}$ Halm and colleagues concluded that echocardiography did not provide additional prognostic information beyond known clinical risk factors. Conversely, other researchers have concluded that systolic dysfunction predicts worsened postoperative outcomes ${ }^{36}{ }^{37}$ However, closer examination of these studies also shows that echocardiographically derived ejection fraction performed poorly at stratifying cardiac risk. For example, Flu and colleagues concluded that asymptomatic ventricular dysfunction was associated with increased risk in a prospective cohort study of 1005 patients having vascular surgery. ${ }^{36}$ However, asymptomatic dysfunction had a likelihood ratio for predicting 30 day cardiac events of only 1.3 , compared with 4.2 for symptomatic congestive heart failure, which is a known risk factor. ${ }^{2}$ Similarly, Rohde and colleagues concluded that ventricular dysfunction was associated with increased risk in 570 patients having non-cardiac surgery, but its likelihood ratio was relatively poor at $1.8 .^{37}$

Secondly, resting echocardiography does not perform well at quantifying perioperative risk attributable to coronary artery disease. It does identify fixed wall motion abnormalities that suggest previous myocardial infarction. However, in the absence of inducible ischaemia, which is instead identified by stress testing, fixed defects are not associated with increased perioperative risk. ${ }^{38}{ }^{39}$ The inability of resting echocardiography to identify inducible ischaemia also limits its capacity to help to target perioperative $\beta$ blockade, which has its best risk-benefit profile in people with inducible ischaemia. ${ }^{40}$

Thirdly, echocardiography was associated with considerably increased rates of new use of $\beta$ blocker in patients at low to intermediate risk who had not had stress testing. As echocardiography cannot identify ideal candidates for $\beta$ blockade - namely, those with inducible ischaemia ${ }^{40}$ - this increased rate of $\beta$ blockade may, in part, have explained the increased mortality in these same subgroups. Specifically, perioperative $\beta$ blockade caused increased mortality in the participants in the Perioperative Ischemic Evaluation (POISE) trial, ${ }^{3}$ and it was associated with either harm or no effect in patients at low to intermediate risk in a large cohort study. ${ }^{41}$ The basis for the increased use of $\beta$ blockers in these subgroups remains unclear and warrants further research. Echocardiography may have provided information that was misinterpreted and led to unnecessary $\beta$ blockade. For example, $\beta$ blockers might have been instituted on the basis of the presence of fixed wall motion abnormalities, which are not associated with increased risk. ${ }^{38} 39$ Conversely, aggressive ordering of both echocardiography and perioperative $\beta$ blockade (regardless of the information derived from the echocardiograms) in patients at low to intermediate risk may be a characteristic of a certain type of physician's practice.

Finally, even when preoperative echocardiography identifies ventricular dysfunction, clinicians have no treatments of proved efficacy to reduce associated perioperative risks. Thus far, no randomised trials have evaluated perioperative medical treatment for congestive heart failure. ${ }^{42}$ Previously evaluated interventions, such as $\beta$ blockers or $\alpha_{2}$ adrenergic agonists, ${ }^{343}$ focused on preventing complications related to coronary artery disease. In our study, rates of new prescriptions for angiotensin converting enzyme inhibitors or angiotensin receptor blockers were significantly increased among patients who had preoperative echocardiography. These prescriptions may therefore have represented newly instituted treatment for asymptomatic systolic dysfunction identified by preoperative echocardiography. Although these drugs are recommended for treating systolic dysfunction in the non-operative setting, ${ }^{44}$ their effects in the perioperative setting remain unknown. If anything, people have raised concerns about recent use of angiotensin converting enzyme inhibitors and angiotensin receptor blockers causing perioperative hypotension, ${ }^{45}$ which is itself associated with mortality. ${ }^{3}$ However, the differential mortality across subgroups in our study was not mirrored by similar differences in new prescriptions for angiotensin converting enzyme inhibitors or angiotensin receptor blockers, suggesting that these drugs were not causally related to mortality. 


\section{Limitations}

Our study has several limitations. As an observational study, it does not prove a causal link between echocardiography and postoperative mortality. Our findings therefore warrant confirmation by other multicentre studies across different settings and data sources. These confirmatory studies should probably include a randomised trial of routine preoperative echocardiography, as has been done for preoperative cardiac stress testing. ${ }^{46}$ Such a trial is better suited to showing causal links but will require a large sample size. Specifically, based on a $7.5 \%$ one year mortality rate with conventional care, 9046 participants are needed to show a $20 \%$ relative risk reduction with preoperative echocardiography (two sided $\alpha=0.05$ and $80 \%$ power). Secondly, our administrative data sources do not generally identify postoperative complications accurately, ${ }^{19}$ and they have limited information on test results, inpatient drugs, and causes of death. Such information would have helped to explain the mechanisms by which echocardiography may influence outcomes. These specific data should therefore be measured by future prospective cohort studies of preoperative echocardiography.

Finally, our data sources did not capture detailed clinical characteristics, thereby limiting our ability to examine specific subgroups that may benefit from preoperative echocardiography. For example, the current guidelines of the American Heart Association and American College of Cardiology recommend preoperative echocardiography only for people with dyspnoea of unknown cause or recent worsening of known congestive heart failure. ${ }^{4}$ Similarly, echocardiography may help to establish whether a suspicious systolic murmur is caused by previously undiagnosed aortic stenosis. As administrative databases do not capture these details, our study does not negate the role of echocardiography in such circumstances. Overall, using preoperative echocardiography for specific diagnostic indications is reasonable; however, our results would suggest that, in the absence of such indications, echocardiography does not provide clinically useful information to improve perioperative care.

\section{Implications for future research}

The relatively common use of preoperative echocardiography and its lack of association with improved outcomes highlight several additional areas for future research in perioperative medicine. More prospective cohort studies are needed to determine whether echocardiography provides prognostic information with clinically useful likelihood ratios. These studies should collect detailed measurements on characteristics such as functional capacity to help to determine whether any subgroups derive better prognostic information. If echocardiography does not show prognostic accuracy that is independent of conventional and more easily measured risk factors, it is highly unlikely to serve as useful test for guiding clinical care. In addition, randomised trials are needed to evaluate potential interventions, such as perioperative treatment with angiotensin converting enzyme inhibitors or altered perioperative fluid management, for improving the outcomes of patients with ventricular dysfunction. In the absence of proved interventions, clinicians will have few avenues for improving clinical care and outcomes on the basis of the results of preoperative echocardiography.

\section{Conclusions}

This population based cohort study found that preoperative echocardiography was not associated with improved survival after major elective non-cardiac surgery. Our findings cast doubt on the usefulness of preoperative echocardiography for improving perioperative outcomes. Furthermore, they highlight the importance of research to stratify patients' perioperative risk better and to develop efficacious interventions that decrease perioperative complications related to ventricular dysfunction.

Contributors: DNW, WSB, PCA, and AL contributed to the conception and design of the study. DNW and PCA contributed to the analysis, and all authors contributed to the interpretation. DNW drafted the article; all authors revised it critically for important intellectual content and approved the final version submitted for publication. DNW is the guarantor.

Funding: DNW is supported by a clinician-scientist award from the Canadian Institutes of Health Research. DNW, WSB, and KK are supported by merit awards from the Department of Anesthesia at the University of Toronto. WSB is the R Fraser Elliot Chair of Cardiac Anesthesia at the University Health Network. PCA is supported by a career investigator award from the Heart and Stroke Foundation of Ontario. This study was supported in part by the Institute for Clinical Evaluative Sciences, which is itself supported in part by the Ontario Ministry of Health and Long-Term Care. The study sponsor had no role in the design and conduct of the study; collection, management, analysis, and interpretation of the data; or preparation, review, and approval of the manuscript. The opinions, results, and conclusions are those of the authors, and no endorsement by the Ontario Ministry of Health and Long-Term Care or the Institute for Clinical Evaluative Sciences is intended or should be inferred.

Competing interests: All authors have completed the Unified Competing Interest form at http://www.icmje.org/coi_disclosure.pdf (available on request from the corresponding author) and declare: no support from any company for the submitted work; no financial relationships with any companies that might have an interest in the submitted work in the previous three years; and no non-financial interests that may be relevant to the submitted work.

Ethical approval: Sunnybrook Health Sciences Centre gave research ethics approval for the study.

Data sharing: No additional data available.

1 Weiser TG, Regenbogen SE, Thompson KD, Haynes AB, Lipsitz SR, Berry WR, et al. An estimation of the global volume of surgery: a modelling strategy based on available data. Lancet 2008;372:139-44.

2 Lee TH, Marcantonio ER, Mangione CM, Thomas EJ, Polanczyk CA, Cook EF, et al. Derivation and prospective validation of a simple index for prediction of cardiac risk of major noncardiac surgery. Circulation 1999;100:1043-9.

3 Devereaux PJ, Yang H, Yusuf S, Guvatt G, Leslie K, Villar JC, et al. Effects of extended-release metoprolol succinate in patients undergoing non-cardiac surgery (POISE trial): a randomised controlled trial. Lancet 2008;371:1839-47.

4 Fleischmann KE, Beckman JA, Buller CE, Calkins H, Fleisher LA, Freeman WK, et al. 2009 ACCF/AHA focused update on perioperative beta blockade incorporated into the ACC/AHA 2007 guidelines on perioperative cardiovascular evaluation and care for noncardiac surgery: a report of the American College of Cardiology Foundation/American Heart Association Task Force on Practice Guidelines. Circulation 2009;120:e169-276.

5 Ford MK, Beattie WS, Wijeysundera DN. Prediction of perioperative cardiac complications and mortality by the revised cardiac risk index: a systematic review. Ann Intern Med 2010;152:26-35.

6 Wijeysundera DN, Beattie WS, Austin PC, Hux JE, Laupacis A. Non-invasive cardiac stress testing before elective major non-cardiac surgery: population based cohort study. BMJ 2010;340:b5526.

7 Wijeysundera DN, Austin PC, Beattie WS, Hux JE, Laupacis A. A population-based study of anesthesia consultation before major non-cardiac surgery. Arch Intern Med 2009;169:595-602.

8 Wijeysundera DN, Austin PC, Beattie WS, Lux JE, Laupacis A. Outcomes and processes-of-care related to preoperative medical consultation. Arch Intern Med 2010;170:1365-74.

9 Halm EA, Browner WS, Tubau JF, Tateo IM, Mangano DT. Echocardiography for assessing cardiac risk in patients having noncardiac surgery. Ann Intern Med 1996;125:433-41.

10 Hux JE, Ivis F, Flintoft V, Bica A. Diabetes in Ontario: determination of prevalence and incidence using a validated administrative data algorithm. Diabetes Care 2002;25:512-6. 1 Institute for Clinical Evaluative Sciences. Canadian Institute for Health Information Discharge Abstract Database: a validation study. (ICES investigative report.) ICES, 2006.

12 Tu K, Campbell NRC, Chen ZL, Cauch-Dudek KJ, McAllister FA. Accuracy of administrative databases in identifying patients with hypertension. Open Med 2007;1:E18-26.

13 Williams JI, Young W. Appendix: a summary of studies on the quality of health care administrative databases in Canada. 1996. www.ices.on.ca/file/Practice2-appendix.pdf.

14 Wijeysundera DN, Beattie WS, Austin PC, Hux JE, Laupacis A. Epidural anaesthesia and survival after intermediate-to-high risk non-cardiac surgery: a population-based cohort study. Lancet 2008;372:562-9. 


\section{What is already known on this topic}

Preoperative resting echocardiography is commonly used to stratify patients for risk of perioperative cardiac complications Echocardiography provides information on ventricular dysfunction and valvular abnormalities, as well as fixed wall motion abnormalities that are suggestive of previous myocardial infarction

Information derived from echocardiography may not provide additional prognostic information when combined with readily available clinical risk factors

\section{What this study adds}

Preoperative echocardiography was not associated with improved overall survival in patients having major elective non-cardiac surgery

These findings cast doubts on value of preoperative echocardiography for improving perioperative care and outcomes

15 Canadian Institute for Health Information. Technical supplement: health care in Canada 2005. 2005. http://secure.cihi.ca/cihiweb/products/HCIC Tech Report 2005 e.pdf.

16 Bourne RB, DeBoer D, Hawker G, Kreder H, Mahomed N, Paterson JM, et al. Total hip and knee replacement. Chapter 5 in: Tu JV, Pinfold SP, McColgan P, Laupacis A, eds. Access to health service in Ontario: ICES atlas. Institute for Clinical Evaluative Sciences, 2005. Available at: www.ices.on.ca/file/Chp5_v5.pdf.

17 Alter DA, Stukel TA, Newman A. Proliferation of cardiac technology in Canada: a challenge to the sustainability of Medicare. Circulation 2006:113:380-7.

18 Fleisher LA, Eagle KA, Shaffer T, Anderson GF. Perioperative- and long-term mortality rates after major vascular surgery: the relationship to preoperative testing in the Medicare population. Anesth Analg 1999;89:849-55.

19 Romano PS, Schembri ME, Rainwater JA. Can administrative data be used to ascertain clinically significant postoperative complications? Am J Med Qual 2002;17:145-54.

20 Landesberg G, Shatz V, Akopnik I, Wolf YG, Mayer M, Berlatzky Y, et al. Association of cardiac troponin, CK-MB, and postoperative myocardial ischemia with long-term survival after major vascular surgery. J Am Coll Cardiol 2003;42:1547-54.

21 Wijeysundera DN, Austin PC, Hux JE, Beattie WS, Buckley DN, Laupacis A. Development of an algorithm to identify preoperative medical consultations using administrative data. Med Care 2009;47:1258-64.

22 Choudhry NK, Soumerai SB, Normand SL, Ross-Degnan D, Laupacis A, Anderson GM. Warfarin prescribing in atrial fibrillation: the impact of physician, patient, and hospital characteristics. Am J Med 2006;119:607-15.

23 Quan H, Sundararajan V, Halfon P, Fong A, Burnand B, Luthi JC, et al. Coding algorithms for defining comorbidities in ICD-9-CM and ICD-10 administrative data. Med Care 2005;43:1130-9.

24 White RH, Gettner S, Newman JM, Trauner KB, Romano PS. Predictors of rehospitalization for symptomatic venous thromboembolism after total hip arthroplasty. N Engl J Med 2000;343:1758-64

25 Quan H, Parsons GA, Ghali WA. Assessing accuracy of diagnosis-type indicators for flagging complications in administrative data. J Clin Epidemiol 2004;57:366-72.

26 Du Plessis V, Beshiri R, Bollman RD, Clemeson H. Definitions of "rural." Agriculture and rural working paper series, number 61. 2002. www.statcan.ca/english/research/21-601$\mathrm{MIE} / 21-601-\mathrm{MIE} 2002061$.htm

27 Rubin DB. The design versus the analysis of observational studies for causal effects: parallels with the design of randomized trials. Stat Med 2007;26:20-36.

28 Birkmeyer JD, Siewers AE, Finlayson EV, Stukel TA, Lucas FL, Batista I, et al. Hospital volume and surgical mortality in the United States. N Engl J Med 2002;346:1128-37.

29 Austin PC. Propensity-score matching in the cardiovascular surgery literature from 2004 to 2006: a systematic review and suggestions for improvement. $J$ Thorac Cardiovasc Surg 2007;134:1128-35.

30 Austin PC. The performance of different propensity score methods for estimating marginal odds ratios. Stat Med 2007;26:3078-94.

31 Liang KY, Zeger SL. Longitudinal data analysis using generalized linear models. Biometrika 1986;73:13-22.

32 Daneman N, Simor AE, Redelmeier DA. Validation of a modified version of the national nosocomial infections surveillance system risk index for health services research. Infect Control Hosp Epidemiol 2009;30:563-9.
33 Neumayer L, Hosokawa P, Itani K, El-Tamer M, Henderson WG, Khuri SF. Multivariable predictors of postoperative surgical site infection after general and vascular surgery: results from the patient safety in surgery study. J Am Coll Surg 2007;204:1178-87.

34 Waisbren E, Rosen H, Bader AM, Lipsitz SR, Rogers SO Jr, Eriksson E. Percent body fat and prediction of surgical site infection. J Am Coll Surg 2010;210:381-9.

35 Beattie WS, Abdelnaem E, Wijeysundera DN, Buckley DN. A meta-analytic comparison of preoperative stress echocardiography and nuclear scintigraphy imaging. Anesth Analg 2006;102:8-16.

36 Flu W, van Kuijk JP, Hoeks SE, Kuiper R, Schouten O, Goei D, et al. Prognostic implications of asymptomatic left ventricular dysfunction in patients undergoing vascular surgery. Anesthesiology 2010;112:1316-24.

37 Rohde LE, Polanczyk CA, Goldman L, Cook EF, Lee RT, Lee TH. Usefulness of transthoracic echocardiography as a tool for risk stratification of patients undergoing major noncardiac surgery . Am J Cardiol 2001:87:505-9.

38 Etchells E, Meade M, Tomlinson G, Cook D. Semiquantitative dipyridamole myocardial stress perfusion imaging for cardiac risk assessment before noncardiac vascular surgery: a meta-analysis. J Vasc Surg 2002;36:534-40.

39 Poldermans D, Arnese M, Fioretti PM, Salustri A, Boersma E, Thomson IR, et al. Improved cardiac risk stratification in major vascular surgery with dobutamine-atropine stress echocardiography. J Am Coll Cardiol 1995;26:648-53.

40 Poldermans D, Boersma E, Bax JJ, Thomson IR, van de Ven LL, Blankenstein JD, et al. The effect of bisoprolol on perioperative mortality and myocardial infarction in high-risk patients undergoing vascular surgery. N Engl J Med 1999;341:1789-94.

41 Lindenauer PK, Pekow P, Wang K, Mamidi DK, Gutierrez B, Benjamin EM. Perioperative beta-blocker therapy and mortality after major noncardiac surgery. N Engl $J$ Med 2005;353:349-61.

42 Hernandez AF, Newby LK, O'Connor CM. Preoperative evaluation for major noncardiac surgery: focusing on heart failure. Arch Intern Med 2004;164:1729-36.

43 Wijeysundera DN, Bender JS, Beattie WS. Alpha-2 adrenergic agonists for the prevention of cardiac complications among patients undergoing surgery. Cochrane Database Syst Rev 2009;4:CD004126.

44 Hunt SA, Abraham WT, Chin MH, Feldman AM, Francis GS, Ganiats TG, et al. ACC/AHA 2005 guideline update for the diagnosis and management of chronic heart failure in the adult: a report of the American College of Cardiology/American Heart Association Task Force on Practice Guidelines. Circulation 2005;112:e154-235.

45 Rosenman DJ, McDonald FS, Ebbert JO, Erwin PJ, LaBella M, Montori VM. Clinical consequences of withholding versus administering renin-angiotensin-aldosterone system antagonists in the preoperative period. $J$ Hosp Med 2008;3:319-25.

46 Poldermans D, Bax JJ, Schouten O, Neskovic AN, Paelinck B, Rocci G, et al. Should major vascular surgery be delayed because of preoperative cardiac testing in intermediate-risk patients receiving beta-blocker therapy with tight heart rate control? $J$ Am Coll Cardiol 2006;48:964-9.

Accepted: 26 May 2011

Cite this as: $B M J 2011 ; 342: \mathrm{d} 3695$ 


\section{Tables}

\section{Table 1| Preoperative characteristics of entire cohort. Values are numbers (percentages) unless stated otherwise}

Echocardiogram ( $n=40084)$ No echocardiogram ( $n=224739)$ Absolute standardised difference (\%)

\section{Demographics}

\begin{tabular}{|c|c|c|c|}
\hline Female sex & $18079(45.1)$ & $118780(52.9)$ & 15.7 \\
\hline Mean (SD) age (years) & $70.7(9.5)$ & $67.0(10.8)$ & 36.9 \\
\hline \multicolumn{4}{|l|}{ Fifth of income: } \\
\hline First (lowest) & 7809 (19.5) & $40604(18.1)$ & 3.6 \\
\hline Second & $8595(21.4)$ & $46142(20.5)$ & 2.2 \\
\hline Third & $7918(19.8)$ & $44897(20.0)$ & 0.5 \\
\hline Fourth & $7690(19.2)$ & $44877(20.0)$ & 2.0 \\
\hline Fifth (highest) & $7974(19.9)$ & $47564(21.2)$ & 3.2 \\
\hline Missing & $98(0.2)$ & $655(0.3)$ & 2.0 \\
\hline Rural residence & $4898(12.2)$ & $34405(15.3)$ & 9.0 \\
\hline \multicolumn{4}{|l|}{ Comorbid disease } \\
\hline Coronary artery disease & $9374(23.4)$ & $20712(9.2)$ & 39.2 \\
\hline Congestive heart failure & $2174(5.4)$ & $3950(1.8)$ & 19.4 \\
\hline Atrial fibrillation & $2398(6.0)$ & $4830(2.1)$ & 19.9 \\
\hline Cardiac valvular disease ${ }^{*}$ & $692(1.7)$ & $604(0.3)$ & 14.1 \\
\hline Mechanical cardiac valve $\dagger$ & $305(0.8)$ & $340(0.2)$ & 8.5 \\
\hline Cerebrovascular disease & $2126(5.3)$ & $5443(2.4)$ & 15.1 \\
\hline Peripheral vascular disease & $7647(19.1)$ & $15243(6.8)$ & 37.3 \\
\hline Hypertension & 30964 (77.2) & $138374(61.6)$ & 34.3 \\
\hline Diabetes mellitus & $10741(26.8)$ & $43159(19.2)$ & 18.1 \\
\hline Thromboembolic disease & $273(0.7)$ & $1160(0.5)$ & 2.6 \\
\hline Pulmonary disease & $4604(11.5)$ & $15873(7.1)$ & 15.2 \\
\hline Renal disease & $1731(4.3)$ & $4363(1.9)$ & 13.9 \\
\hline Liver disease & $433(1.1)$ & $2107(0.9)$ & 2.0 \\
\hline Rheumatological disease & $728(1.8)$ & $4587(2.0)$ & 1.5 \\
\hline Peptic ulcer disease & $580(1.4)$ & $2273(1.0)$ & 3.7 \\
\hline Hemiplegia or paraplegia & $360(0.9)$ & $1115(0.5)$ & 4.8 \\
\hline Dementia & $306(0.8)$ & $1477(0.7)$ & 1.2 \\
\hline \multicolumn{4}{|l|}{ Malignancy: } \\
\hline Primary & $7971(19.9)$ & $42079(18.7)$ & 3.0 \\
\hline Metastatic & $2407(6.0)$ & $15380(6.8)$ & 3.3 \\
\hline \multicolumn{4}{|l|}{ Preoperative consultations } \\
\hline Anaesthesiology $\ddagger$ & $28650(71.5)$ & 118805 (52.9) & 39.1 \\
\hline \multicolumn{4}{|l|}{ Internal medicine§: } \\
\hline General internist & $11943(29.8)$ & $49447(22.0)$ & 17.9 \\
\hline Cardiologist & $12071(30.1)$ & $15010(6.7)$ & 63.3 \\
\hline \multicolumn{4}{|l|}{ Preoperative testing } \\
\hline Non-invasive stress testing & $15694(39.2)$ & $15356(6.8)$ & 83.4 \\
\hline
\end{tabular}

\section{*History of aortic stenosis or mitral stenosis.}

†Mechanical aortic valve replacement or mechanical mitral valve replacement within 10 years before index surgical procedure.

‡Outpatient consultation within 60 days before surgery.

$\S$ Consultation by general internist or cardiologist within 120 days before index surgical procedure. ${ }^{21}$

\Within 180 days before index surgery 
Table 2| Perioperative characteristics of entire cohort. Values are numbers (percentages) unless stated otherwise

\begin{tabular}{|c|c|c|c|}
\hline & Echocardiogram $(n=40084)$ & No echocardiogram ( $n=224739)$ & Absolute standardised difference $(\%)$ \\
\hline \multicolumn{4}{|l|}{ Hospital type } \\
\hline Teaching hospital & $12943(32.3)$ & $74131(33.0)$ & 1.5 \\
\hline \multicolumn{4}{|l|}{ Procedure quarter*: } \\
\hline First (lowest) & $8458(21.1)$ & $57389(25.5)$ & 10.4 \\
\hline Second & $10207(25.5)$ & $53198(23.7)$ & 4.2 \\
\hline Third & $10692(26.7)$ & $55996(24.9)$ & 4.1 \\
\hline Fourth (highest) & $10727(26.8)$ & $58156(25.9)$ & 2.0 \\
\hline \multicolumn{4}{|l|}{ Procedure } \\
\hline Abdominal aortic aneurysm repair & $4288(10.7)$ & $6115(2.7)$ & 32.4 \\
\hline Carotid endarterectomy & $3172(7.9)$ & $5710(2.5)$ & 24.5 \\
\hline Peripheral vascular bypass & $2684(6.7)$ & $7802(3.5)$ & 14.6 \\
\hline Total hip replacement & $7143(17.8)$ & 52667 (23.4) & 13.9 \\
\hline Total knee replacement & $11277(28.1)$ & $79998(35.6)$ & 16.2 \\
\hline Large bowel surgery & $5807(14.5)$ & $47153(21.0)$ & 17.1 \\
\hline Liver resection & $216(0.5)$ & $1539(0.7)$ & 2.6 \\
\hline Whipple procedure & $171(0.4)$ & $1358(0.6)$ & 2.8 \\
\hline Pneumonectomy or lobectomy & $2400(6.0)$ & $6560(2.9)$ & 15.1 \\
\hline Gastrectomy or oesophagectomy & $1116(2.8)$ & $4547(2.0)$ & 5.2 \\
\hline Nephrectomy & $1459(3.6)$ & $8921(4.0)$ & 2.1 \\
\hline Cystectomy & $351(0.9)$ & $2369(1.1)$ & 2.0 \\
\hline \multicolumn{4}{|l|}{ Perioperative care } \\
\hline Epidural anaesthesia & $11859(29.6)$ & $46997(20.9)$ & 20.1 \\
\hline Arterial line & $18669(46.6)$ & $58312(25.9)$ & 44.1 \\
\hline Central venous line & $7561(18.9)$ & $19693(8.8)$ & 29.6 \\
\hline Pulmonary artery catheter & $2321(5.8)$ & $4113(1.8)$ & 21.0 \\
\hline
\end{tabular}

*Divided into quarters of approximately equal patient numbers, on basis of total volume of eligible procedures over entire study period. ${ }^{28}$ 


\begin{tabular}{|c|c|c|c|}
\hline & Echocardiogram ( $n=35$ 498) & No echocardiogram ( $n=35$ 498) & Absolute standardised difference (\%) \\
\hline \multicolumn{4}{|l|}{ Demographics } \\
\hline Female sex & $16503(46.5)$ & $16589(46.7)$ & 0.4 \\
\hline Mean (SD) age (years) & $70.7(9.6)$ & $70.7(9.5)$ & 0.9 \\
\hline \multicolumn{4}{|l|}{ Fifth of income: } \\
\hline First (lowest) & $6931(19.5)$ & $6973(19.6)$ & 0.3 \\
\hline Second & $7567(21.3)$ & $7606(21.4)$ & 0.2 \\
\hline Third & $7003(19.7)$ & $6993(19.7)$ & $<0.1$ \\
\hline Fourth & $6834(19.3)$ & $6755(19.0)$ & 0.8 \\
\hline Fifth (highest) & $7070(19.9)$ & $7082(20.0)$ & 0.3 \\
\hline Missing & $93(0.3)$ & $89(0.3)$ & $<0.1$ \\
\hline Rural residence & $4525(12.7)$ & $4421(12.5)$ & 0.6 \\
\hline \multicolumn{4}{|l|}{ Comorbid disease } \\
\hline Coronary artery disease & $8011(22.6)$ & $8021(22.6)$ & $<0.1$ \\
\hline Congestive heart failure & $1860(5.2)$ & $1866(5.3)$ & 0.4 \\
\hline Atrial fibrillation & $2012(5.7)$ & $2084(5.9)$ & 0.9 \\
\hline Cardiac valvular disease $^{*}$ & $446(1.3)$ & $425(1.2)$ & 0.9 \\
\hline Mechanical cardiac valve $\dagger$ & $255(0.7)$ & $225(0.6)$ & 1.2 \\
\hline Cerebrovascular disease & $1877(5.3)$ & $1917(5.4)$ & 0.4 \\
\hline Peripheral vascular disease & $5921(16.7)$ & $5811(16.4)$ & 0.8 \\
\hline Hypertension & $27185(76.6)$ & $27361(77.1)$ & 1.2 \\
\hline Diabetes mellitus & $9451(26.6)$ & $9562(26.9)$ & 0.7 \\
\hline Thromboembolic disease & $241(0.7)$ & $244(0.7)$ & $<0.1$ \\
\hline$\underline{\text { Pulmonary disease }}$ & $3920(11.0)$ & $3987(11.2)$ & 0.6 \\
\hline Renal disease & $1438(4.1)$ & $1478(4.2)$ & 0.6 \\
\hline Liver disease & $385(1.1)$ & $378(1.1)$ & $<0.1$ \\
\hline Rheumatological disease & $675(1.9)$ & $650(1.8)$ & 0.7 \\
\hline Peptic ulcer disease & $520(1.5)$ & $530(1.5)$ & $<0.1$ \\
\hline$\underline{\text { Hemiplegia or paraplegia }}$ & $322(0.9)$ & $350(1.0)$ & 1.0 \\
\hline Dementia & $283(0.8)$ & $282(0.8)$ & $<0.1$ \\
\hline \multicolumn{4}{|l|}{ Malignancy: } \\
\hline Primary & $7027(19.8)$ & $7124(20.1)$ & 0.8 \\
\hline Metastatic & $2196(6.2)$ & $2162(6.1)$ & 0.4 \\
\hline \multicolumn{4}{|l|}{ Preoperative consultations } \\
\hline Anaesthesiology $\ddagger$ & $24762(69.8)$ & $24886(70.1)$ & 0.7 \\
\hline \multicolumn{4}{|l|}{ Internal medicine§: } \\
\hline General internist & $10981(30.9)$ & $11170(31.5)$ & 1.3 \\
\hline Cardiologist & $8595(24.2)$ & $8290(23.4)$ & 1.9 \\
\hline \multicolumn{4}{|l|}{ Preoperative testing } \\
\hline Non-invasive stress testing & $11502(32.4)$ & $11227(31.6)$ & 1.7 \\
\hline
\end{tabular}

*History of aortic stenosis or mitral stenosis.

†Mechanical aortic valve replacement or mechanical mitral valve replacement within 10 years before index surgical procedure.

ҒOutpatient consultation within 60 days before surgery.

§Consultation by general internist or cardiologist within 120 days before index surgical procedure. ${ }^{21}$

TWithin 180 days before index surgery. 
Table 4| Perioperative characteristics of matched cohort. Values are numbers (percentages) unless stated otherwise

\begin{tabular}{|c|c|c|c|}
\hline & Echocardiogram ( $n=35498)$ & No echocardiogram ( $n=35498)$ & Absolute standardised difference (\%) \\
\hline \multicolumn{4}{|l|}{ Hospital type } \\
\hline Teaching hospital & $12016(33.8)$ & $11969(33.7)$ & 0.2 \\
\hline \multicolumn{4}{|l|}{ Procedure quarter ${ }^{\star}:$} \\
\hline First (lowest) & $7354(20.7)$ & $7313(20.6)$ & 0.2 \\
\hline Second & $8688(24.5)$ & $8635(24.3)$ & 0.5 \\
\hline Third & $9569(27.0)$ & 9559 (26.9) & 0.2 \\
\hline Fourth (highest) & $9887(27.9)$ & $9991(28.1)$ & 0.4 \\
\hline \multicolumn{4}{|l|}{ Procedure } \\
\hline Abdominal aortic aneurysm repair & $3128(8.8)$ & $3062(8.6)$ & 0.7 \\
\hline Carotid endarterectomy & $2800(7.9)$ & $2794(7.9)$ & $<0.1$ \\
\hline Peripheral vascular bypass & $2206(6.2)$ & $2180(6.1)$ & 0.4 \\
\hline Total hip replacement & $6571(18.5)$ & $6639(18.7)$ & 0.5 \\
\hline Total knee replacement & $10480(29.5)$ & $10554(29.7)$ & 0.4 \\
\hline Large bowel surgery & $5271(14.8)$ & $5230(14.7)$ & 0.3 \\
\hline Liver resection & $189(0.5)$ & $172(0.5)$ & $<0.1$ \\
\hline Whipple procedure & $158(0.4)$ & $139(0.4)$ & $<0.1$ \\
\hline Pneumonectomy or lobectomy & $2100(5.9)$ & $2148(6.1)$ & 0.8 \\
\hline Gastrectomy or oesophagectomy & $1005(2.8)$ & $985(2.8)$ & $<0.1$ \\
\hline Nephrectomy & $1300(3.7)$ & $1296(3.7)$ & $<0.1$ \\
\hline Cystectomy & $290(0.8)$ & $299(0.8)$ & $<0.1$ \\
\hline \multicolumn{4}{|l|}{ Perioperative care } \\
\hline Epidural anaesthesia & $9932(28.0)$ & 9906 (27.9) & 0.2 \\
\hline Arterial line & $15751(44.4)$ & $15718(44.3)$ & 0.2 \\
\hline Central venous line & $5939(16.7)$ & $5836(16.4)$ & 0.8 \\
\hline Pulmonary artery catheter & $1914(5.4)$ & $1894(5.3)$ & 0.4 \\
\hline
\end{tabular}

*Divided into quarters of approximately equal patient numbers, on basis of total volume of eligible procedures over entire study period. ${ }^{28}$ 
Table 5| Outcomes and processes of care in matched cohort. Values are as numbers (percentages) unless stated otherwise

\begin{tabular}{|c|c|c|c|}
\hline & Echocardiogram ( $n=35$ 498) & No echocardiogram ( $n=35498$ ) & Relative risk (95\% Cl) \\
\hline \multicolumn{4}{|l|}{ Preoperative procedures* } \\
\hline Coronary angiography & $1267(3.6)$ & $1204(3.4)$ & $1.05(0.98$ to 1.14$)$ \\
\hline Percutaneous coronary intervention & $223(0.6)$ & $273(0.8)$ & 0.82 (0.69 to 0.97$)$ \\
\hline CABG surgery & $87(0.2)$ & $84(0.2)$ & $1.03(0.77$ to 1.40$)$ \\
\hline \multicolumn{4}{|l|}{ Outcomes } \\
\hline 30 day death & $693(2.0)$ & $609(1.7)$ & 1.14 (1.02 to 1.27$)$ \\
\hline 1 year death & $2620(7.4)$ & $2460(6.9)$ & 1.07 (1.01 to 1.12$)$ \\
\hline 30 day surgical site infection & $4690(13.2)$ & 4570 (12.9) & $1.03(0.98$ to 1.06$)$ \\
\hline New drug use $†$ & $(n=25755)$ & $(n=25755)$ & \\
\hline$\beta$ blocker & 2649 (10.3) & $1916(7.4)$ & 1.38 (1.31 to 1.46$)$ \\
\hline Statin & $1500(5.8)$ & $1245(4.8)$ & 1.20 (1.11 to 1.30$)$ \\
\hline ACE inhibitor & $1867(7.3)$ & $1255(4.9)$ & $1.49(1.39$ to 1.49$)$ \\
\hline Angiotensin receptor blocker & $635(2.5)$ & $492(1.9)$ & $1.29(1.15$ to 1.45$)$ \\
\hline RAS blockerł & $2422(9.4)$ & $1699(6.6)$ & $1.42(1.34$ to 1.51$)$ \\
\hline
\end{tabular}

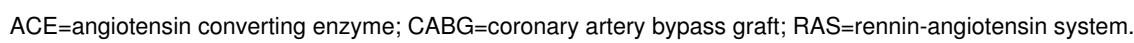

*Within 180 days before index surgery.

†Subgroup aged $\geq 66$ years; prescription during period 1-120 days before hospital admission, but no prescription during period between 121 and 365 days before hospital admission.

ҒACE inhibitor or angiotensin receptor blocker. 


\begin{tabular}{|c|c|c|}
\hline \multirow[b]{2}{*}{ Cohort/subgroup } & \multicolumn{2}{|c|}{1 year mortality } \\
\hline & Relative risk $(95 \% \mathrm{Cl})$ & Interaction* \\
\hline Entire matched cohort & 1.07 (1.01 to 1.12$)$ & NA \\
\hline \multicolumn{3}{|l|}{ Subgroups } \\
\hline \multicolumn{3}{|l|}{ Hospital teaching status: } \\
\hline Teaching & $1.02(0.94$ to 1.12$)$ & \multirow[t]{2}{*}{$P=0.30$} \\
\hline Non-teaching & $1.09(1.01$ to 1.16$)$ & \\
\hline \multicolumn{3}{|c|}{ Hospital procedure quarter: } \\
\hline First (lowest) & $1.13(1.01$ to 1.28$)$ & \multirow[t]{4}{*}{$P=0.36$} \\
\hline Second & $1.01(0.90$ to 1.12$)$ & \\
\hline Third & 1.10 (1.00 to 1.22$)$ & \\
\hline Fourth (highest) & $1.02(0.93$ to 1.13$)$ & \\
\hline \multicolumn{3}{|l|}{ Age: } \\
\hline$<70$ years & $1.07(1.01$ to 1.14$)$ & \multirow[t]{2}{*}{$P=0.87$} \\
\hline$\geq 70$ years & $1.06(0.96$ to 1.18$)$ & \\
\hline \multicolumn{3}{|l|}{ Coronary artery disease: } \\
\hline Present & $1.05(0.95$ to 1.15$)$ & \multirow[t]{2}{*}{$P=0.70$} \\
\hline Absent & 1.07 (1.01 to 1.14$)$ & \\
\hline \multicolumn{3}{|l|}{ Congestive heart failure: } \\
\hline Present & $1.04(0.90$ to 1.21$)$ & \multirow[t]{2}{*}{$P=0.80$} \\
\hline Absent & 1.07 (1.01 to 1.13$)$ & \\
\hline \multicolumn{3}{|l|}{ Pulmonary disease: } \\
\hline Present & 1.07 (0.96 to 1.20$)$ & \multirow[t]{2}{*}{$P=0.96$} \\
\hline Absent & $1.07(1.01$ to 1.14$)$ & \\
\hline \multicolumn{3}{|c|}{ Concurrent cardiac stress test and RCRI†: } \\
\hline Concurrent stress test & $1.01(0.92$ to 1.11$)$ & \\
\hline \multicolumn{3}{|l|}{ No concurrent stress test: } \\
\hline RCRI: 0 points & 1.44 (1.14 to 1.82$)$ & \multirow[t]{3}{*}{$P=0.02$} \\
\hline RCRI: $1-2$ points & $1.10(1.02$ to 1.18$)$ & \\
\hline RCRI: $\geq 3$ points & $1.00(0.87$ to 1.13$)$ & \\
\hline \multicolumn{3}{|l|}{ Procedure: } \\
\hline Vascular & $1.00(0.90$ to 1.12$)$ & \multirow[t]{3}{*}{$P=0.16$} \\
\hline Abdominal or thoracic & 1.06 (1.00 to 1.13$)$ & \\
\hline Orthopaedic & $1.20(1.04$ to 1.38$)$ & \\
\hline
\end{tabular}

$\mathrm{RCRl}=$ revised cardiac risk index.

*Tests whether treatment effects differed significantly between subgroups.

†Given previously described interaction between stress testing and RCRI, ${ }^{6}$ this subgroup analysis involved exact matching on both characteristics. $\ddagger$ No significant interaction $(P=0.26)$ between the $R C R I$ score and preoperative echocardiography among patients who had cardiac stress testing. 
Table $7 \mid$ Association of preoperative echocardiography with new preoperative drugs ${ }^{\star}$ within subgroups

\begin{tabular}{|c|c|c|c|c|}
\hline \multirow{2}{*}{$\begin{array}{l}\text { Concurrent cardiac stress } \\
\text { test/RCRI }\end{array}$} & \multicolumn{2}{|c|}{ New $\beta$ blocker } & \multicolumn{2}{|c|}{ New statin } \\
\hline & Relative risk $(95 \% \mathrm{Cl})$ & Interaction† & Relative risk $(95 \% \mathrm{Cl})$ & Interaction $†$ \\
\hline Concurrent stress test & 1.23 (1.14 to 1.33$)$ & & 1.06 (0.95 to 1.18$)$ & \\
\hline \multicolumn{5}{|l|}{ No concurrent stress test: } \\
\hline RCRI: 0 points & 1.72 (1.47 to 2.01$)$ & $P<0.001$ & 1.54 (1.29 to 1.86$)$ & $P=0.002$ \\
\hline RCRI: $1-2$ points & 1.57 (1.41 to 1.74$)$ & & 1.30 (1.14 to 1.47$)$ & \\
\hline $\mathrm{RCRI}: \geq 3$ points & 1.18 (0.96 to 1.47$)$ & & 1.06 (0.94 to 1.19$)$ & \\
\hline
\end{tabular}

$\mathrm{RCRI}=$ revised cardiac risk index.

*Prescription during period 1-120 days before hospital admission, but no prescription during period between 121 and 365 days before hospital admission; subgroup aged 66 years or older.

$\ddagger T e s t s$ whether treatment effects differed significantly between subgroups; no significant subgroup effect (interaction $\mathrm{P}=0.71$ ) for association of preoperative echocardiography with new use of angiotensin converting enzyme inhibitor or angiotensin receptor blocker. 